\title{
Genetic aspects of the Pi system
}

\author{
P. J. L. CoOK* \\ M.B.
}

MRC Human Biochemical Genetics Unit

\section{Summary}

$\alpha_{1}$-Antitrypsin can be shown to be polymorphic by starch gel electrophoresis. At present 19 different alleles are known which are inherited in an autosomal pattern and constitute the Pi system. In one phenotype called $\mathrm{Pi}$ type $\mathrm{ZZ}$ there is a virtual deficiency of plasma $\alpha_{1}$-antitrypsin and about 230 such babies are expected in England and Wales every year.

$\alpha_{1}$-ANTITRYPSIN is a plasma protein of mol. wt. of around 60,000 , which contains sialic acid. It has this name because it migrates as an $\alpha_{1}$-globulin on paper electrophoresis and because it inhibits trypsin and other proteolytic enzymes in vitro. Its function in vivo is unknown.

In 1965 Fagerhol and Braend demonstrated by a rather unusual form of starch gel electrophoresis that this protein is polymorphic. That is to say a number of different types of $\alpha_{1}$-antitrypsin can be

\footnotetext{
*Correspondence: Dr P. J. L. Cook, The Galton Laboratory, University College London, Wolfson House, 4 Stephenson Way, London NW1 2HE.
}

found in the Caucasian population. At about the same time Laurell and Eriksson (1963) noted an association between a deficiency of this plasma protein and emphysema among young adults. More recently an association between this deficiency and neonatal liver disease has been described. There are many reviews of the genetic (Fagerhol and Laurell, 1970), pulmonary (Hutchison, 1973) and hepatic (Sharp, 1971) aspects of this subject.

Fagerhol and Braend found that one electrophoretic pattern on their starch gel was common and this is now called Pi type MM. A pattern with additional bands running faster than usual was called FM and one with bands running slower than usual $\mathrm{P}_{\mathrm{b}}$ type MS. Since then at least 19 apparent alleles have been found which have been named $\mathbf{B}, \mathbf{D}, \mathbf{E}, \mathbf{F}, \mathbf{F}^{2}$ $\mathbf{G}, \mathbf{I}, \mathbf{L}, \mathbf{M}, \mathbf{P}, \mathbf{S}, \mathbf{V}, \mathbf{W}, \mathbf{W}^{2}, \mathbf{X}, \mathbf{Y}, \mathbf{Y}^{2}, \mathbf{Z}$ and null These alleles have been named so that their relative order in the alphabet indicates their relative mobilities on a starch gel. These alleles could in theory be combined in 190 ways to give 190 different genotypes. In practice most types are so rare that we have only

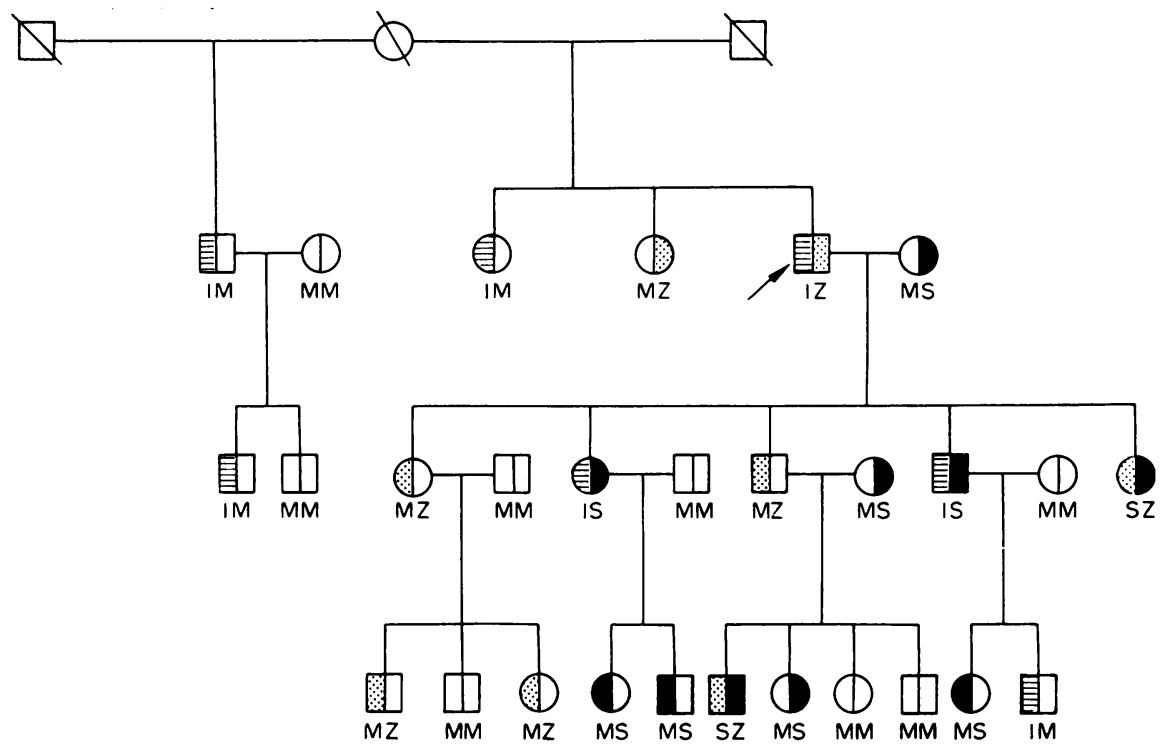

Fig. 1. A family demonstrating the autosomal inheritance of the $\mathrm{Pi}$ alleles $\mathbf{P i}^{\mathbf{M}}, \mathbf{P i}^{\mathbf{S}}, \mathbf{P i}^{\mathrm{Z}}$, and $\mathbf{P i}^{\mathbf{I}}$. 
seen 25 amongst 10,000 samples during the last 5 years and a further 11 have been found in other countries.

These Pi genes have been shown to be inherited in a straightforward autosomal pattern, as illustrated in Fig. 1. The results of the two commonest types of marriage are:

\begin{tabular}{lrrc}
\hline \multirow{2}{*}{ Parents } & \multicolumn{3}{c}{ Children } \\
\cline { 2 - 4 } & MM & MS & Exceptions \\
\hline MM $\times$ MM & 1185 & 0 & 4 \\
MS $\times$ MM & 124 & 125 & 0 \\
\hline
\end{tabular}

These exceptions could be attributed to in vitro effects: ageing which increases the electrophoretic mobility and infection which slows the Pi bands. At present we do not know which chromosome carries the Pi genes, but we do know that they are on the same chromosome as the $\mathrm{Gm}$ genes which determine the constant part of the heavy chain of IgG (GeddeDahl et al., 1972). However, these genes are a long way apart and there is no reason to suspect any functional connection between them.

The majority of the $\mathrm{Pi}$ alleles produce normal quantities of $\alpha_{1}$-antitrypsin which we think functions normally. Only a few genes produce low levels. $\mathbf{P i}^{\mathbf{Z}}$ produces about $10 \%$ of normal, $\mathbf{P i} \mathbf{S}^{\mathbf{S}}, \mathbf{P i}^{\mathbf{W}}$ and $\mathbf{P i}^{\mathbf{P}}$ produce about $60 \%$ of normal and $\mathbf{P i}^{\text {inull }}$ apparently produces nothing; at least when considered in terms of the plasma concentration. $\mathbf{P i} \mathbf{Z}$ is difficult and $\mathbf{P} \mathbf{p}^{\text {null }}$ impossible to detect by the usual method of starch gel electrophoresis, so that the distinction between MM, MZ and Mnull is difficult. However, the MZ type can be detected by two dimensional crossed antigen antibody electrophoresis. In the past it has been claimed that $\mathbf{P i} \mathbf{M M}, \mathbf{M Z}$ and $\mathrm{ZZ}$ phenotypes could be distinguished by biochemical or immunological assay alone. This is not so because healthy individuals of other phenotypes such as MS, SS and $\mathrm{SZ}$ can give over-lapping assay results as shown in Fig. 2. In addition inflammation, surgery, pregnancy, contraceptive therapy and steroid therapy can double the plasma $\alpha_{1}$-antitrypsin concentration in every phenotype. The use of 'hospital controls' can be misleading.

The frequencies of the Pi types at birth in England and Scotland are:

\begin{tabular}{lccc}
\hline & & \multicolumn{2}{c}{$\begin{array}{c}\text { Mean healthy adult } \\
\text { plasma } \alpha_{1} \text {-antitrypsin }\end{array}$} \\
\cline { 3 - 4 } Pi type & $\begin{array}{c}\text { \% of newborn } \\
\text { population }\end{array}$ & as \% of $\mathrm{MM}$ & in $\mathrm{mg} / 100 \mathrm{ml}$ \\
\hline MM & $86 \%$ & 100 & $257 \pm 76$ \\
MS & 9 & 80 & $229 \pm 60$ \\
MZ & 3 & 65 & $171 \pm 42$ \\
SS & 0.25 & 60 & $150 \pm 35$ \\
SZ & $0 \cdot 2$ & 35 & $92 \pm 28$ \\
ZZ & 0.029 & 10 & $17 \pm 10$ \\
Others & 1.5 & - & - \\
\hline
\end{tabular}

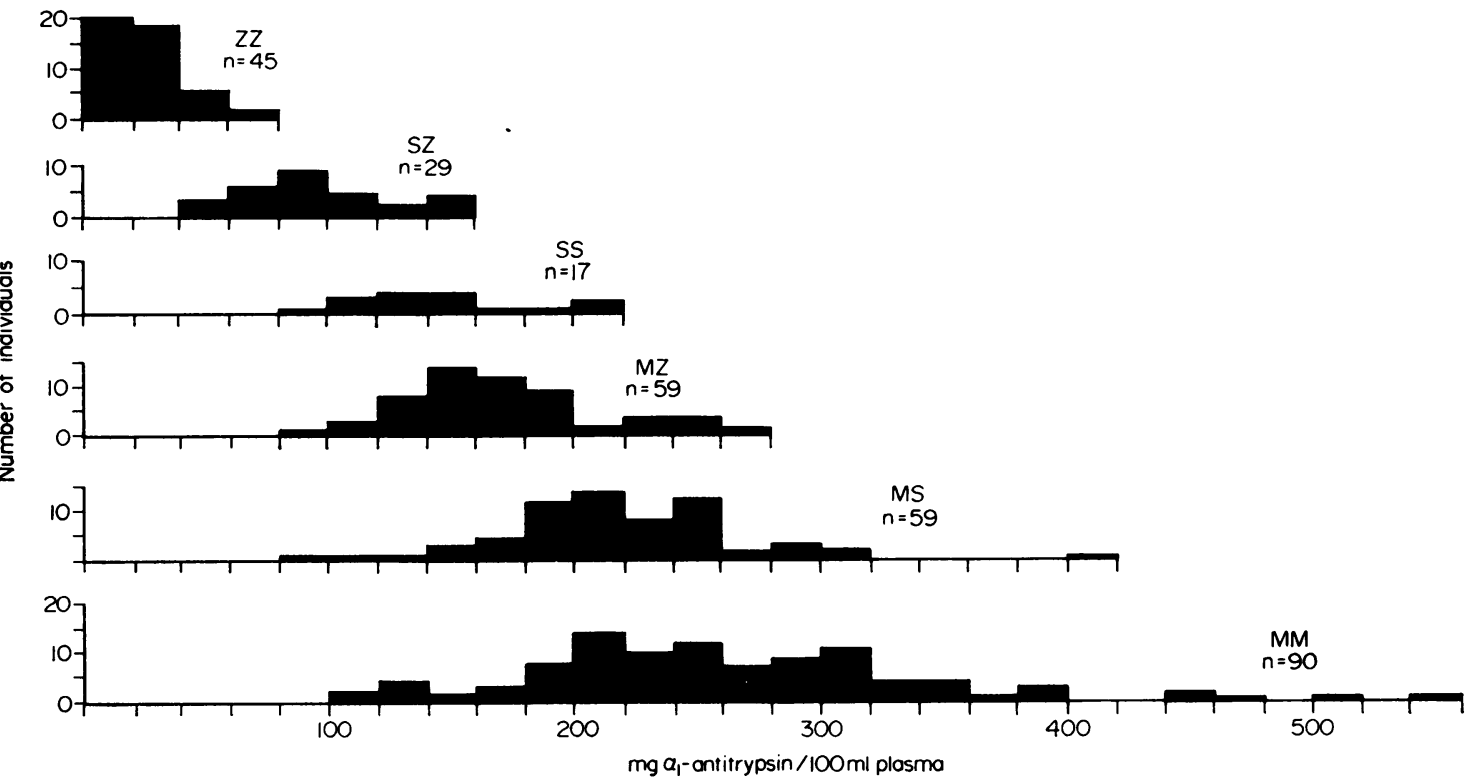

FIG. 2. $\alpha_{1}$-Antitrypsin plasma concentrations of individuals classified by Pi type. Assays were carried out by the immunodiffusion method and expressed in terms of a commercial standard (Behringwerke) which had been assayed against a 'partially purified standard'. Thirty-nine of the $\mathrm{ZZ}$ samples were from patients, but all other samples were taken from apparently healthy individuals. 
$\mathrm{Pi} \mathrm{ZZ}$ is usually the only type of clinical importance although Pi SZ can sometimes cause confusion on assay and a few (perhaps $2 \%$ ) SZ individuals can present with a similar clinical picture. We estimate that one baby in 3460 is born with $\alpha_{1}$-antitrypsin deficiency (Pi type ZZ), so that in England and Wales about 230 are born each year. We do not think that more than $10-15 \%$ of these babies will suffer from liver disease, because of twenty-six Pi ZZ individuals who did not present with liver disease none gave a history of jaundice and none had lost brothers or sisters in childhood with jaundice.

The majority of parents of deficient individuals are of Pi type $M Z$, but because the gene frequency of $\mathbf{P i}^{\mathbf{Z}}=0.017$ each parent has a 1 in 60 chance of being $\mathrm{Pi} \mathrm{ZZ}$. When a Pi ZZ individual is detected it is our normal practice to obtain a repeat sample of blood to confirm the findings and to test blood from the parents, sibs and children of the $\mathrm{Pi} \mathrm{ZZ}$ individual. The chance of a sib being of Pi type $\mathrm{ZZ}$ is usually 1 in 4 ( 1 in 2 with a deficient parent), but the chance of a second Pi ZZ child suffering from liver disease when a previous sib has had liver disease remains to be quantified.

\section{References}

Fagerhol, M.K. \& Braend, M. (1965) Serum prealbumins: polymorphism in man. Science, $149,986$.

Fagerhol, M.K. \& Laurell, C.-B. (1970) The Pi systeminherited variants of serum $\alpha_{1}$-antitrypsin. In: Progress in Medical Genetics (Ed. by A. G. Steinberg and A. G. Bearn), vol. 7, 96. Heinemann, London.

Gedde-Dahl, T., Fagerhol, M.K., Cook, P.J.L. \& Noades, J. (1972) Autosomal linkage between the $\mathrm{Gm}$ and $\mathrm{Pi}$ loci in man. Annals of Human Genetics, 35, 393.

Hutchison, D.C.S. (1973) $\alpha_{1}$-Antitrypsin deficiency and pulmonary emphysema; the role of the proteolytic enzymes and their inhibitor. British Journal of Diseases of the Chest. 67, 171 .

Laurell, C.-B. \& Eriksson, S. (1963) The electrophoretic $\alpha_{1}$-globulin pattern of serum in $\alpha_{1}$-antitrypsin deficiency. The Scandinavian Journal of Clinical and Laboratory Investigation, 15, 132.

Sharp, H.L. (1971) Alpha-1-antitrypsin deficiency. Hospital Practice, 5, 83. 